\title{
Diffusion of COVID-19 among children and adolescents during the second and third waves of the pandemic in Italy
}

\author{
Francesca Bassi ${ }^{1}$ D $\cdot$ Mattia Doria ${ }^{2}$
}

Received: 14 July 2021 / Revised: 24 November 2021 / Accepted: 26 November 2021 / Published online: 27 January 2022

(c) The Author(s), under exclusive licence to Springer-Verlag GmbH Germany, part of Springer Nature 2021

\begin{abstract}
This paper explores COVID-19 diffusion among children and adolescents (up to 19 years old) in Italy using the publicly available data that were collected and released by the Italian National Institute of Health (ISS). We consider in more detail the so-called second and third waves of the pandemic in Italy and explore the relationship between schools opening and the diffusion of COVID-19, which is a highly debated topic in the recent reference literature. We analyse the dynamics of COVID-19 incidence in the country as a whole and in its individual regions. Moreover, we compare the regions in which different levels of restrictions were imposed during the pandemic as well as different school closure calendars. We found there to be a significant correlation between the dynamics of the COVID-19 infections among young people in Italy and school closures during both the second and the third waves of the pandemic.

Conclusion: Specifically, we found school closures to have mitigated the spread of the infection, especially among patients between the ages of 14 and 19.

\section{What is Known:}

- The relationship between the opening of schools and the diffusion of COVID-19 is a debated topic.

- SARS-CoV-2 diffusion among school-aged adolescents is almost twice as that among children.

- SARS-CoV-2 is a mild disease for infants and children.

What is New:

- We analysed original data on the diffusion of COVID-19 among children and adolescents in Italy.

- We calculated incidence of COVID-19 with reference to school-age classes and compared over time in the whole country and in the regions

of Italy.

- We analysed incidence dynamics considering school closures and other restrictions imposed by the local and national authorities to limit virus diffusion.
\end{abstract}

Keywords COVID-19 Incidence $\cdot$ Correlation $\cdot$ School closure

\section{Abbreviations}

ISS Italian National Institute of Health

MERS Middle East respiratory syndrome

SARS Severe acute respiratory syndrome

Communicated by Peter de Winter

Francesca Bassi

francesca.bassi@unipd.it

Mattia Doria

mattiadoria@fimp.pro

1 Department of Statistical Sciences, University of Padova, via C. Battisti 241, 35121 Padua, Italy

2 Italian Federation of Pediatricians (FIMP), via Parigi 11, 00185 Rome, Italy
FIMP Italian Federation of Pediatricians

ISTAT Italian National Statistical Institute

\section{Introduction}

The scope of this paper is to explore COVID-19 illness, caused by SARS-CoV-2, diffusion among children and adolescents (up to 19 years of age) in Italy using the publicly available data that were collected and released by the Italian National Institute of Health (ISS) through its website. The ISS publishes periodic reports on the pandemic and distributes the data related to this phenomenon to the researchers who request for them to fulfil specific research needs. 
In this paper, we consider in more detail the so-called second and third waves of the pandemic in Italy. The first wave of the pandemic officially started at the beginning of March 2020 when the first cases of COVID-19 were diagnosed in Northern Italy, specifically in Veneto and Lombardia. The second wave occurred from the month of September 2020 to the end of the year, while the third wave took place in 2021 (Fig. 1).

Various studies have been published on the diffusion of COVID-19 among young patients and the outcomes of the infection in this portion of the population. Leeb et al. [1], for example, studied COVID-19 diffusion among school-aged children and adolescents (5-17 years of age) in the USA; they found that incidence among adolescents (12-17 years old) was almost twice as that among children (5-11 years old). Götzinger et al. [2] conducted a multicentre study in 25 European countries on individuals younger than 19; they confirmed that COVID-19 is a mild disease for infants and children, and only a small proportion developed severe symptoms. Similar findings were reported by Gupta et al. [3], who compared the diffusion of COVID-19 among children with that of two other coronavirus diseases, namely Middle East respiratory syndrome (MERS) and severe acute respiratory syndrome (SARS). Another debated topic is of the role that children play in virus transmission. Dattner et al. [4], using data collected from a sample of households in Israel, found significantly lower infectivity for children under 10 years of age as compared to the rest of the population.

The relationship between the opening of schools and the diffusion of COVID-19 is a debated topic in the recent reference literature; a majority of the published papers identified a non-negligible association between these two phenomena. Amodio et al. [5], for instance, used spatial data to investigate the diffusion of COVID-19 in relation to schools opening in the Italian region of Sicilia and found a positive and significant increase in the number of cases that corresponded to the opening of schools. Stein-Zamir et al. [6] reported a rapid increase in COVID-19 cases among the students and staff of high schools in Israel that corresponded with schools reopening after the lockdown of Spring 2020. In addition, Aiano et al. [7] documented an increase in COVID-19 cases in Great Britain after schools reopened in September 2020; secondary school students were found to be more likely to be affected by COVID-19 than the younger ones. On the other hand, Ludvigsson [8], through a meta-analysis of published papers, concluded that children are highly unlikely to be the main drivers of the pandemic. Specifically, the author reported that the opening of schools did not have an effect on the mortality rates for COVID-19 in older people. Gras-Le Guen [9] recommended that schools be reopened during the pandemic in order to maintain students' well-being and relied on the fact that no conclusive evidence could be found regarding the effects of school closures and viral transmission at the population level. The problem of students' well-being was addressed in many papers that have been recently published and that described especially the detrimental effects on children mental health caused by school closure and lockdown (see, as an example, [10]). UNESCO, in March 2021, organised a high-level ministerial meeting to examine the most urgent challenges created by the pandemic and threatening education. In particular, during the meeting, there was discussion on how to keep schools open while ensuring a safe learning environment, starting from the evidence that school closure for the pandemic resulted in a reduction both of health and well-being, as well as of educational outcomes [11].
Fig. 1 New diagnosed cases of COVID-19, weekly moving average, 1 March 2020-1 May 2021, total population, Italy. Source: Created by the authors based on the data obtained from Italian Civil Protection (https:// github.com/pcm-dpc/COVID19)

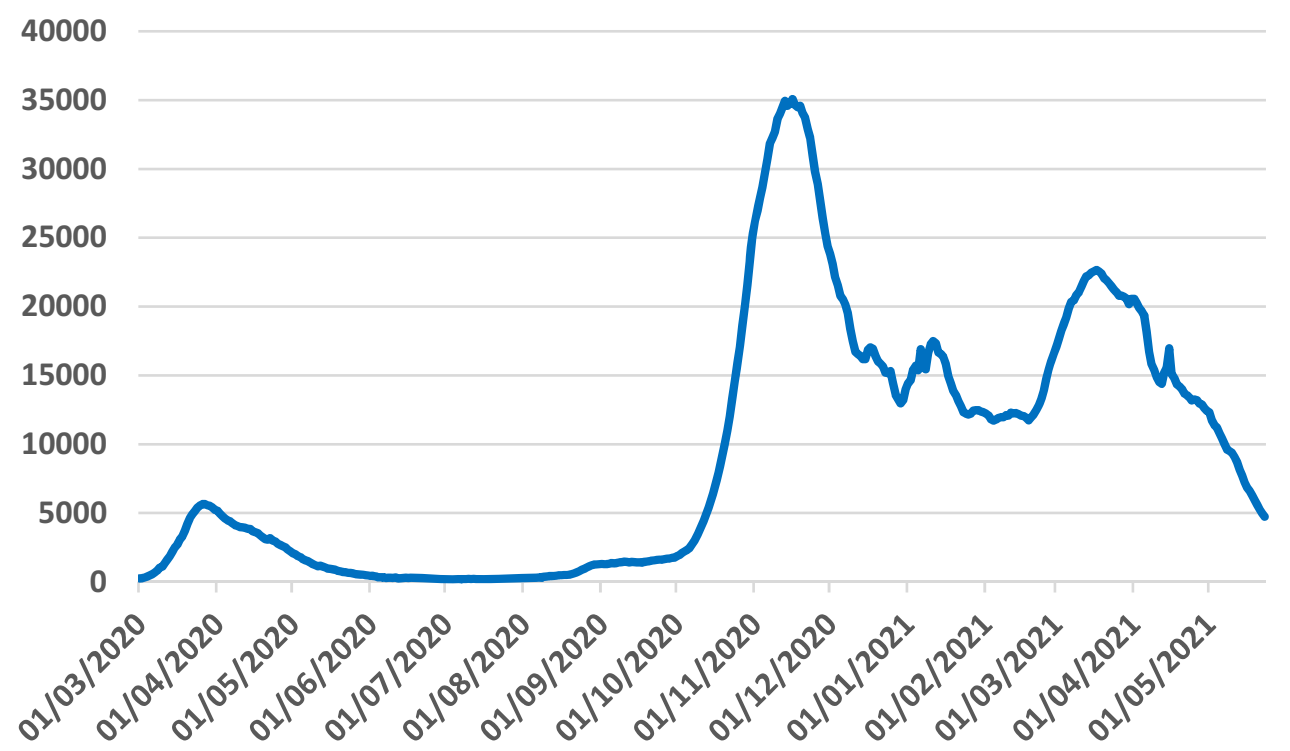


A primary analysis of the diffusion of COVID-19 among young people during the second wave and in reference to the decision to implement distance learning in Italy can be found in the analyses published in [12]. In the current paper, we consider the same data but in an updated format, and we propose further and new analyses. Moreover, we also explore the outbreak of COVID-19 cases among young patients during 2021 (until the end of April).

For the analyses of COVID-19 diffusion during the year 2020, we used the monthly data of new diagnoses, hospitalisations, and deaths that was disaggregated for the 19 Italian regions and two autonomous provinces (Bolzano and Trento) for the following age groups: $0-3,4-6,7-11,12-14$, and 15-19. These age groups correspond to the levels of education in Italy: nursery, kindergarten, primary school, secondary school, and high school, respectively. The data are also disaggregated by gender. These data were obtained by the Italian Federation of Pediatricians (FIMP) from the ISS for this research.

For the analyses related to the year 2021, the data used were retrieved from the weekly publications of ISS related to the pandemic in Italy (see, as an example, [13]).

The indicators of incidence were calculated with reference to the Italian population by age and gender on 1 January 2020 that is available on the website of the Italian National Statistical Institute (ISTAT).

Unfortunately, the data for 2020 and 2021 were available to us at different levels of disaggregation-by gender and age intervals corresponding to school levels for 2020 and by 10 -year intervals for 2021 -and different time gapsmonthly for 2020 and weekly for 2021 . However, these data provide a significant amount of information about the diffusion of the virus among the young generation and its relation with school attendance.

Figure 1 depicts the weekly moving average of the daily number of new diagnosed cases of COVID-19 in Italy from 1 March 2020, which was the official beginning of the pandemic in the country, to 1 May 2021. From the graph, it is possible to determine the three waves of the pandemic that affected the country in that period of time. The first wave, which occurred in Spring 2020, was characterised by a large underestimation of cases; the second wave reached its peak around 15 November 2020, with an average number of daily cases equal to 35,000 . The third wave peaked around 15 March 2021, with about 22,000 daily new diagnosed cases.

The rest of the paper is organised as follows: in the "Incidence of COVID-19 among children and adolescents during the first and second waves of the pandemic in Italy" section, we analyse the spread of the virus among young individuals in Italy during the first and second waves of the pandemic. In the "Diffusion of COVID-19 and school closures: a comparison of certain Italian regions" section, we compare the events that occurred in specific Italian regions.
In the "Evolution of the COVID-19 infection among young people: third wave in Italy" section, we explore the diffusion of COVID-19 during the third wave. Finally, in the "Concluding remarks" section, we present concluding remarks and suggest some further developments of the analyses.

\section{Incidence of COVID-19 among children and adolescents during the first and second waves of the pandemic in Italy}

Table 1 reports the number of new cases of COVID-19 that were diagnosed and registered in the ISS database, which are reported on a monthly basis and refer to 2020 (from March to December). The data were disaggregated by gender and age class, as described in the "Introduction". During the initial months of the pandemic, until May, the infection among young people was extremely limited. In Italy, during these months, severe measures were imposed by the government to prevent the spread of the virus; these measures affected children and adolescents more strongly, as all schools were closed, as well as all other activities for children and young people, such as sports, music, parks, and places of gathering. Students were at home almost all the time and exposed to eventual infection only through relatives who stepped out of the house. However, in general, during these first months of 2020, it is quite reasonable to suppose that the COVID19 cases were largely underestimated in Italy for the whole population due to various reasons, such as the unavailability of swabs and the fact that, during the early phase of the pandemic, the World Health Organization (WHO) recommended that only patients with symptoms should be tested [14].

In the following months, during the summer, as can be seen from Fig. 1, the daily cases of COVID-19 almost ceased in Italy. However, in the month of August, they began to increase again, especially among young people of 15-19 years of age. This dynamic becomes clearer when looking at Table 2, which lists the monthly incidence of COVID-19 per 100,000 inhabitants for each age and gender group in Italy. These measures can also be compared to the monthly incidence per 100,000 people from the total population of the country, which is reported in the last row of the table. The extremely low rates of COVID-19 infection among the Italian population can be ascribed to various factors: the strict lockdown imposed during the Spring and, probably, the climate conditions during the Summer. On the other hand, the increase in incidence in August 2020 most likely occurred due to it being the Summer vacation for children and adolescents, during which they are more likely to meet each other.

Another important piece of evidence that emerges from the figures in Table 2 is that there are significant 
Table 1 Monthly diagnosed new cases of COVID-19 by gender and age class, March-December 2020, Italy

\begin{tabular}{|c|c|c|c|c|c|c|c|c|c|c|c|}
\hline Age & & March & April & May & June & July & August & September & October & November & December \\
\hline \multirow[t]{3}{*}{ 0-3 } & Female & 187 & 156 & 102 & 52 & 94 & 181 & 547 & 2,733 & 4,423 & 3,055 \\
\hline & Male & 239 & 177 & 99 & 54 & 110 & 196 & 616 & 2,945 & 4,931 & 3,329 \\
\hline & Total & 426 & 333 & 201 & 106 & 204 & 377 & 1,163 & 5,678 & 9,354 & 6,384 \\
\hline \multirow[t]{3}{*}{ 4-6 } & Female & 83 & 257 & 77 & 55 & 84 & 154 & 419 & 2,570 & 4,632 & 3,327 \\
\hline & Male & 102 & 139 & 78 & 51 & 87 & 149 & 427 & ,2667 & 5,004 & 3,490 \\
\hline & Total & 185 & 396 & 155 & 106 & 171 & 303 & 846 & 5,237 & 9,636 & 6,817 \\
\hline \multirow[t]{3}{*}{$7-11$} & Female & 187 & 504 & 127 & 86 & 122 & 252 & 716 & 7,922 & 13,723 & 8,162 \\
\hline & Male & 172 & 276 & 113 & 97 & 121 & 257 & 742 & 8,642 & 14,702 & 8,876 \\
\hline & Total & 359 & 780 & 240 & 183 & 243 & 509 & 1,458 & 16,564 & 28,425 & 17,038 \\
\hline \multirow[t]{3}{*}{$12-14$} & Female & 158 & 457 & 116 & 59 & 75 & 186 & 573 & 7,063 & 10,102 & 5,631 \\
\hline & Male & 151 & 232 & 131 & 62 & 87 & 182 & 610 & 8,115 & 10,758 & 6,026 \\
\hline & Total & 309 & 689 & 247 & 121 & 162 & 368 & 1,183 & 15,178 & 20,860 & 11,657 \\
\hline \multirow[t]{3}{*}{ 15-19 } & Female & 336 & 513 & 269 & 141 & 133 & 1,206 & 1,267 & 14,104 & 18,691 & 10,006 \\
\hline & Male & 357 & 460 & 228 & 141 & 275 & 1,574 & 1,493 & 16,840 & 19,527 & 10,505 \\
\hline & Total & 693 & 973 & 497 & 282 & 408 & 2,780 & 2,760 & 30,944 & 38,218 & 11,511 \\
\hline
\end{tabular}

differences in the incidence between males and females only in very few comparisons as documented by confidence intervals reported in Table 6 in the Appendix (this result was also confirmed by previous studies; see, for example, [15]). The same evidence emerges for the monthly number of virus-positive hospitalised patients; differences are statistically significant only for very few cases and with a non-systematic trend, as documented by the $t$-test reported in Table 7 in the Appendix. Fortunately, the fatality rate for COVID-19 among children and adolescents is almost negligible: up to 3 May 2021, only 24 COVID-19 patients under the age of 19 had died from a total of more than 500,000 diagnosed cases.
The lowest incidence rate observed for children under 6 years during the entire period covered by Fig. 2, and especially from September, deserves some attention. When going to school, these children do not have to use masks, so they should be particularly exposed to the virus; moreover, nursery and elementary schools did not close during the second wave of the pandemic. This result deserves further investigation also within the scientific debate about the effects on respiratory functions of wearing masks (see, as an example, [16]).

Figure 2 shows the evolution of the monthly incidence of COVID-19 over time during the year 2020 in Italy and compares what happened in the young age classes with that of the overall population. For children under 11 years of age, the monthly

Table 2 Monthly incidences of COVID-19 for 100,000 inhabitants by gender and age class, March-December 2020, Italy

\begin{tabular}{|c|c|c|c|c|c|c|c|c|c|c|c|}
\hline Age & & March & April & May & June & July & August & September & October & November & December \\
\hline \multirow[t]{3}{*}{ 0-3 } & Female & 20.45 & 17.06 & 11.15 & 5.69 & 10.28 & 19.79 & 59.81 & 298.81 & 483.58 & 334.01 \\
\hline & Male & 27.26 & 20.19 & 11.29 & 6.16 & 12.55 & 22.36 & 70.26 & 335.91 & 562.44 & 379.71 \\
\hline & Total & 23.78 & 18.59 & 11.22 & 5.92 & 11.39 & 21.05 & 64.92 & 316.97 & 522.18 & 356.38 \\
\hline \multirow[t]{3}{*}{ 4-6 } & Female & 10.83 & 33.54 & 10.05 & 7.18 & 10.96 & 20.10 & 54.69 & 335.42 & 604.55 & 434.22 \\
\hline & Male & 14.09 & 19.20 & 10.77 & 7.04 & 12.02 & 20.58 & 58.98 & 368.37 & 691.15 & 482.04 \\
\hline & Total & 12.41 & 26.57 & 10.40 & 7.11 & 11.47 & 20.33 & 56.77 & 351.43 & 646.62 & 457.45 \\
\hline \multirow[t]{3}{*}{$7-11$} & Female & 13.20 & 35.57 & 8.96 & 6.07 & 8.61 & 17.79 & 50.54 & 559.16 & 968.62 & 576.10 \\
\hline & Male & 12.87 & 20.65 & 8.45 & 7.26 & 9.05 & 19.22 & 55.50 & 646.44 & $1,099.74$ & 663.94 \\
\hline & Total & 13.04 & 28.33 & 8.72 & 6.65 & 8.82 & 18.48 & 52.95 & 601.53 & $1,032.28$ & 618.75 \\
\hline \multirow[t]{3}{*}{$12-14$} & Female & 17.99 & 52.03 & 13.21 & 6.72 & 8.54 & 21.18 & 65.24 & 804.17 & $1,150.18$ & 641.13 \\
\hline & Male & 18.31 & 28.13 & 15.89 & 7.52 & 10.55 & 22.07 & 73.97 & 984.04 & $1,304.53$ & 730.72 \\
\hline & Total & 18.14 & 40.46 & 14.50 & 7.11 & 9.51 & 21.61 & 69.47 & 891.27 & $1,224.93$ & 684.51 \\
\hline \multirow[t]{3}{*}{ 15-19 } & Female & 22.62 & 34.53 & 18.11 & 9.49 & 8.95 & 81.19 & 85.29 & 949.47 & $1,258.26$ & 673.59 \\
\hline & Male & 25.77 & 33.20 & 16.46 & 10.18 & 19.85 & 113.60 & 107.75 & $1,215.37$ & $1,409.29$ & 758.16 \\
\hline & Total & 24.14 & 33.89 & 17.31 & 9.82 & 14.21 & 96.83 & 96.13 & $1,077.79$ & $1,331.15$ & 400.93 \\
\hline Italy & Total & 174.54 & 167.12 & 46.20 & 12.67 & 11.67 & 36.35 & 76.54 & 611.27 & $1,546.11$ & 808.39 \\
\hline
\end{tabular}




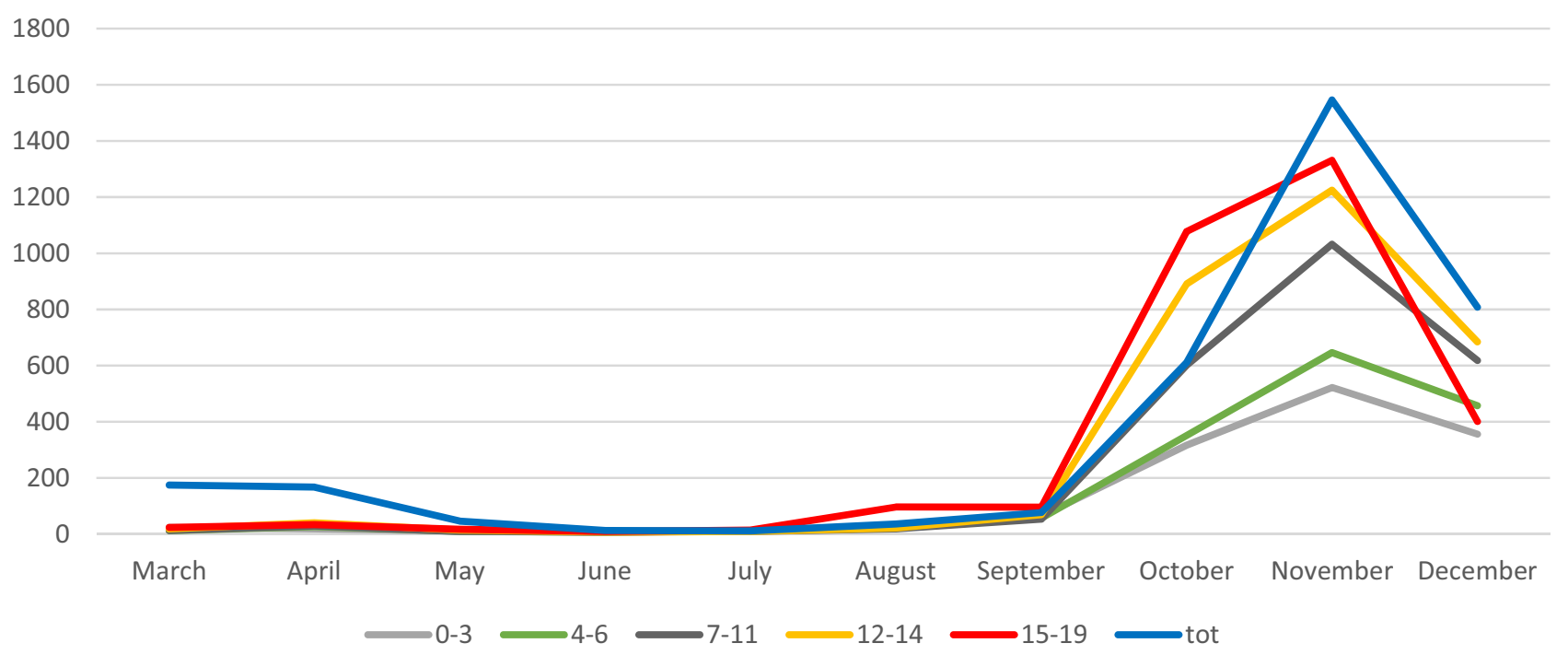

Fig. 2 Monthly incidences of COVID-19 for 100,000 inhabitants, March-December 2020, Italy by young age classes and the whole population

incidence was always lower than the average level. In September and October, after schools opened, ${ }^{1}$ the virus spread more rapidly among secondary and high school students than in the overall population. This is represented in Fig. 2 by the yellow and red lines remaining above the blue one. This tendency had already been revealed in August even though with a lower number of new cases. From November 2020, the incidence in all young age groups became lower than that of the total population.

In Italy, from the end of October, all high schools began to organise online classes for $50-70 \%$ of students, while, from 6 November, $100 \%$ of the teaching for high schools was carried out online until the Christmas holidays in line with the national measures implemented by the government. The dates and the type of schools closed during the last months of 2020 were slightly different in the 19 regions and the two autonomous provinces of Italy. Certain areas of the country anticipated that online teaching would also be carried out in October, as we will discuss in detail in the next paragraph. In November and December, the regions with extremely high incidence (so-called red zones) also ceased the second- and third-year classes of secondary schools.

The dynamics of incidence for the different age classes, which are depicted in Fig. 2, shows a clear correlation with school opening and closing in Italy. However, a causal link cannot be established based on observational data. In the absence of experimental data, in the following sections, we will analyse the information available regarding the incidence in the young age groups in depth, as these emerging correlations with the school calendar require.

\footnotetext{
${ }_{1}^{1}$ In Italy, the school calendar varies slightly across the regions. However, in general, schools open around 10 September and close at the beginning of June.
}

In Fig. 3, we have reported the monthly dynamics through 2020 of the probability of young people being hospitalised if infected; these probabilities refer to the predefined age classes. The high probabilities observed from March to August are directly related to the underestimation of cases. However, it is interesting to underline that, in the following months as well, the age class with the highest probabilities of hospitalisation is that of the youngest children of ages up to 3 years. For the other age classes, the probability of hospitalisation is almost equal to 0 . This evidence of a more severe form of the illness for the youngest children has been confirmed by other studies (see, for example, [17]).

With regard to territorial differences, in Italy, the spread of the pandemic presented different dynamics in many areas. The infections among young people are correlated to the diffusion of the virus in each area, as Fig. 4 illustrates with reference to October 2020 as an example. The figure reports the monthly incidence for 100,000 inhabitants in the 19 regions and two autonomous provinces of Italy. The bars represent the incidence in the young age classes, while the blue line connects the value of incidence relatively to the total population of each area. We consider October 2020 as an example, which was one of the months of that year that had the highest number of diagnosed cases of COVID-19 in Italy (Fig. 1). From Fig. 4, it is possible to see that incidence clearly increases with age in all regions and that it is strictly correlated (Pearson coefficient of correlation $>0.6$ ) to the average value of the same indicator in each area.

Figure 5 contains the same information as Fig. 4 but for November 2020. During this month, in Italy, the second wave of the pandemic reached its peak (Fig. 1). Comparing Figs. 4 and 5 , it is possible to see that, from October to November, the incidence of COVID-19 significantly increased in the overall 


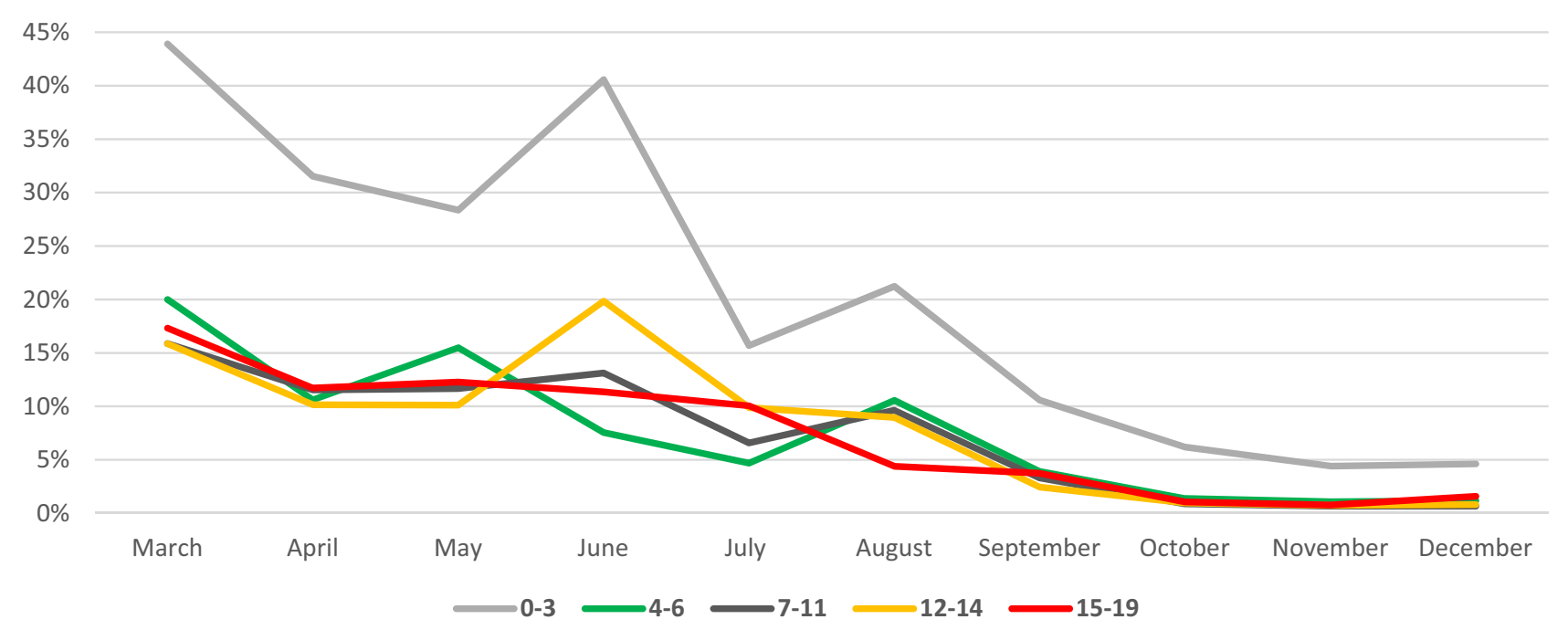

Fig. 3 Probability of hospitalisation if infected by COVID-19 by age class, March-December 2020

population and in the young age classes that we are considering as well, especially among individuals of 15-19 years of age. However, the correlation coefficients (Table 3) are all lower with respect to those calculated for October (with the exception of the age class of 7-11 years). This is another piece of evidence to support that school closures might have affected the diffusion of the virus among young people.

In order to analyse the effect of school closures on the pandemic, it is necessary to consider the other factors that might have affected the spread of the virus as well, especially the restrictions imposed by the Italian government. Moreover, it is necessary to compare over time not only the absolute values of incidence but also the relative variations.

Until 16 October 2020, all schools in Italy were open. Thereafter, certain regions began to close schools, with different percentages of classes provided online, and the regions in which the spread of the virus was greater anticipated school closures. Afterwards, the high values of incidence in almost all areas of the country led to the execution of the decree of the Italian Prime Minister (DPCM) of 3 November 2020 [18], which, among the other measures implemented to contain the pandemic, declared that all high school classes should be conducted online. The same decree introduced restrictions in the Italian regions according to three levels of COVID-19 diffusion in each area, defining the so-called yellow, orange, and red zones. The allocation of each region or autonomous province to the appropriate colour was determined weekly on the basis of 21 indicators related to the probability of infection diffusion, the impact on hospitals, and territorial resilience [19]. In these three types of areas, different restrictions were imposed to limit contact and prevent virus diffusion. More severe restrictions
Fig. 4 Monthly incidence of COVID-19 per 100,000 inhabitants, young age classes and total population of the 19 regions and two autonomous provinces of Italy, October 2020

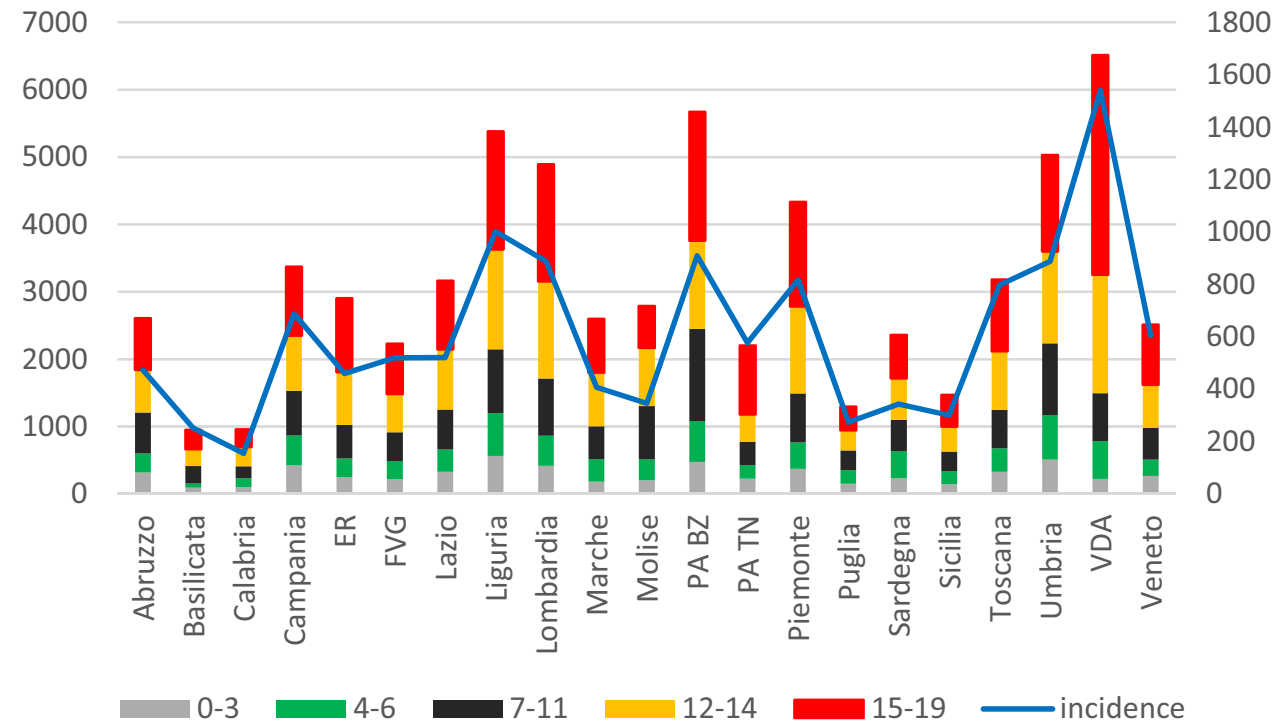


Fig. 5 Monthly incidence of COVID-19 per 100,000 inhabitants, young age classes and total population in the 19 regions and two autonomous provinces, Italy, November 2020

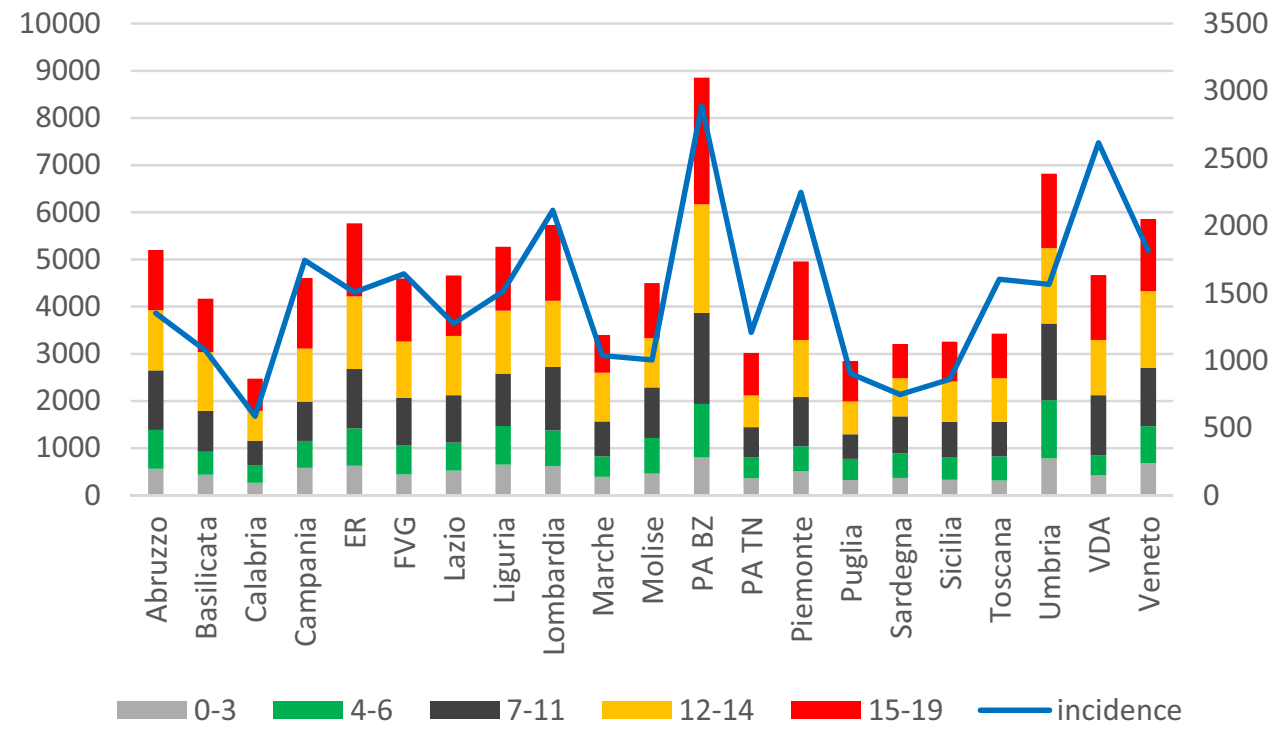

were imposed in red zones, where only essential shops and services could stay open, all other activities were to remain closed, and citizens could leave their homes only to go to work, for health-related reasons, or extremely urgent matters. Moreover, students in the second and third years of secondary schools were to stay home; this was an additional restriction that was imposed in all territories for high schools. In the so-called orange zones, citizens could freely move inside their municipality of residence but could exit it only to go to work, for health-related reasons, or extremely urgent matters. Shops were allowed to open, while all other activities were to remain closed. In yellow zones, citizens were allowed to move freely within the region; bars and restaurants could stay open until 6 p.m. In the whole country, even in the yellow zones, travelling was prohibited from 10 p.m. to 5 a.m. except for work or exceptional reasons. Table 4 summarises the restrictions imposed in the three zones by the decree. With regard to the restrictions associated with school closure, for high schools, they were homogeneous in all regions from 26 October to Christmas, imposed by the decree of the Italian Prime Minister. Other closures, specifically for the second and third years of secondary schools,

Table 3 Correlation coefficients between total monthly incidence of COVID-19 for 100,000 inhabitants and monthly incidences of COVID-19 for 100,000 in the young age class, October and November 2020 , Italy

\begin{tabular}{llllll}
\hline & $\mathbf{0 - 3}$ & $\mathbf{4 - 6}$ & $\mathbf{7 - 1 1}$ & $\mathbf{1 2 - 1 4}$ & $\mathbf{1 5 - 1 9}$ \\
\hline $\begin{array}{c}\text { October 2020, } \\
\text { total popula- }\end{array}$ & 0.829 & 0.791 & 0.661 & 0.896 & 0.967 \\
tion & & & & & \\
$\begin{array}{c}\text { November } \\
\text { 2020, total } \\
\text { population }\end{array}$ & 0.607 & 0.429 & 0.733 & 0.718 & 0.850 \\
\hline
\end{tabular}

were applicable for the regions declared as red zones. Other closures that could possibly affect all levels of school were decided autonomously by certain regions where the local administration judged the pandemic situation to be particularly severe. It is important to note that, in red zones, other activities related to gathering of children and adolescents, such as all types of sports, were also forbidden. In the orange zones, certain activities could continue to be held with the recommended prescription of social distancing.

In the next paragraph, we will compare the evolution of the incidence of COVID-19 during the worst months of the second wave of the pandemic in Italy, which were October and November 2020, taking into account school closures and the other restrictions imposed in each region of the country.

\section{Diffusion of COVID-19 and school closures: a comparison of certain Italian regions}

\section{Lombardia, Friuli Venezia Giulia, and Veneto}

As stated in the previous paragraph, an exploratory analysis of the dynamics of incidence in the whole population and the young age classes during the second wave of the pandemic in Italy indicates the existence of a correlation with school closures. This evidence emerges both at the country level and when looking at the diffusion of the virus in the 19 regions and two autonomous provinces as well.

Figure 6 compares the monthly incidence per 100,000 inhabitants in the three northeastern regions of Italy, which presented the highest number of COVID-19 infections (Table 8 in the Appendix reports $95 \%$ confidence intervals). We have considered the period from September to December. During these months, with reference to the 21 indicators considered by the ISS and the Italian Ministry of Health, different levels of restrictions were 
Table 4 Rules for the red, orange, and yellow zones, decree of 3 November 2020, Italy

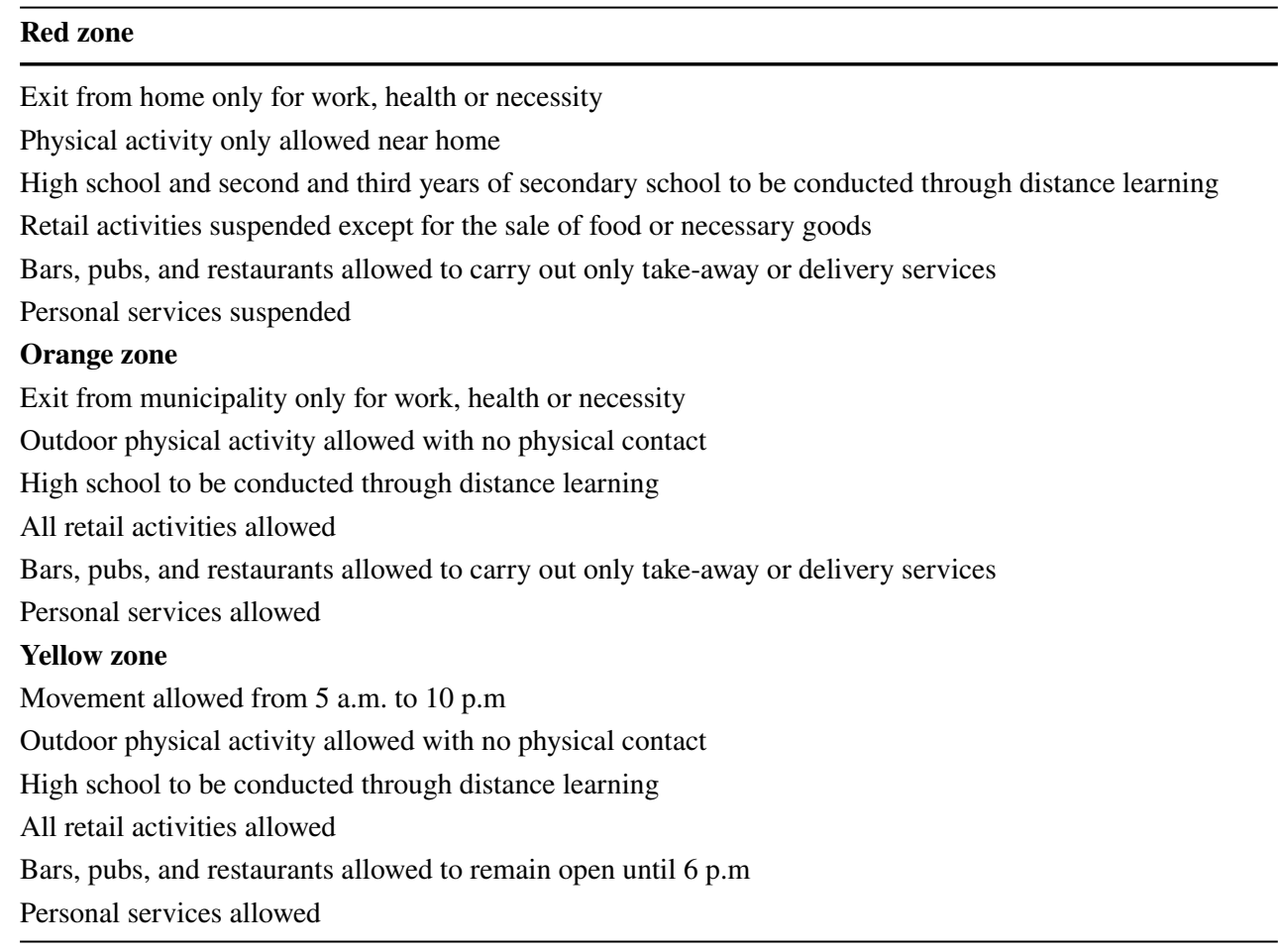

imposed in these regions. Specifically, Lombardia was declared a red zone from 6 to 28 November, orange until 12 December and, subsequently, yellow thereafter. Friuli Venezia Giulia (FVG) was an orange zone from 15 November to 5 December and became a yellow zone after that. Finally, Veneto was always classified as a yellow zone. With regard to schools, all high schools carried out $75 \%$ of their classes online from 26 October, and $100 \%$ from 6 November. In Lombardia, the second and third years of secondary schools carried out $100 \%$ of their lessons online while the region was a red zone. Table 5 summarises the colours assigned to the five Italian regions analysed in this section.

In the three regions, as was in the whole country (Fig. 2), the incidence of COVID-19 increased with the age of the patients. Moreover, it is interesting to note that the incidence among children under the age of 11 (in Italy, this age marks the end of primary school) remained the lowest across the considered four months.

In Lombardia, in October 2020, the virus spread among young people aged between 12 and 19 years more rapidly than in the total population. From November, incidence decreased, returning to a level that was lower than the average. In December, the monthly incidence decreased for all age classes.

Further, in Friuli Venezia Giulia, the monthly incidence for individuals over 11 years of age was higher than the average. In November, it kept growing but at a slower pace than that of the whole population, and, in December, incidence was stable for all ages.

Finally, in Veneto, the monthly incidence continued to grow across the reference period. However, from November, the infection spread more slowly among young people even though the incidence in these classes was extremely highhigher than the average-in October.

\section{Campania and Lazio}

Lazio and Campania are two other Italian regions that are interesting to compare in terms of the dynamics of the COVID-19 pandemic among young people during the second wave. These two regions were affected by very different levels of restrictions. Lazio was a yellow zone the entire time; i.e., the highest possible level of mobility was allowed during the pandemic period, and only those restrictions were applied that were common to the entire country. High schools were closed from 26 October, as in Veneto, while other schools, from nursery to secondary, remained open throughout the pandemic period. Campania was declared a red zone from 15 November to 6 December; this is one of the Italian regions where schools experienced a significantly long period of closure (from 12 October until Christmas holidays) (see Table 5).

Further, these two regions witnessed high levels of incidence of COVID-19 in October 2020, especially in the age classes of over 11 years old, among which the number of cases was greater than the average level (Fig. 7, Table 9 in the Appendix reports $95 \%$ confidence intervals). In Campania, during the month of November, incidence continued to increase. However, among young individuals, it was slower than that in the rest of the population. In December, incidence reduced for all ages. The dynamics of the incidence in Lazio shows a peculiar pattern: it 
Fig. 6 Monthly incidence of COVID-19 per 100,000 inhabitants, total population and young age classes, September-

December 2020, Lombardia, FVG, Veneto

\section{Lombardia}

2500.00

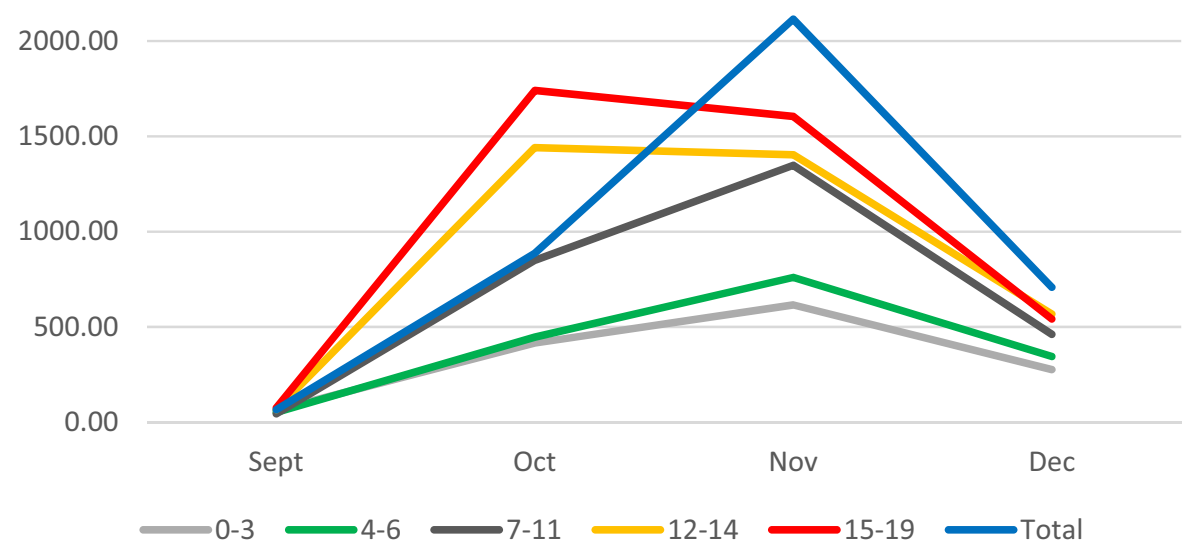

Friuli Venezia Giulia
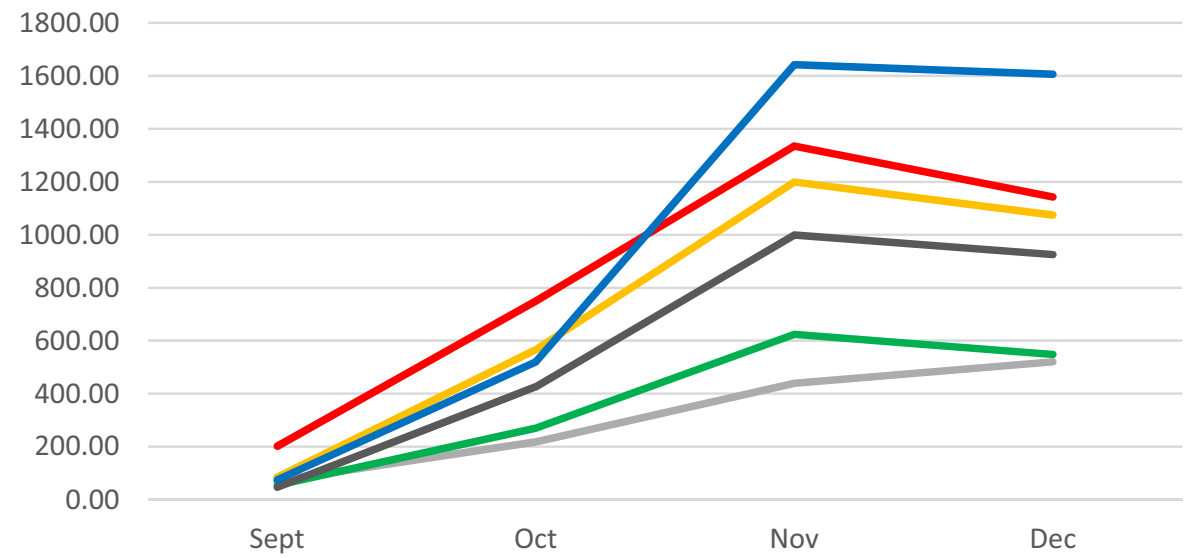

$\longrightarrow$ 0-3 4-6 7-11

\section{Veneto}

2500.00

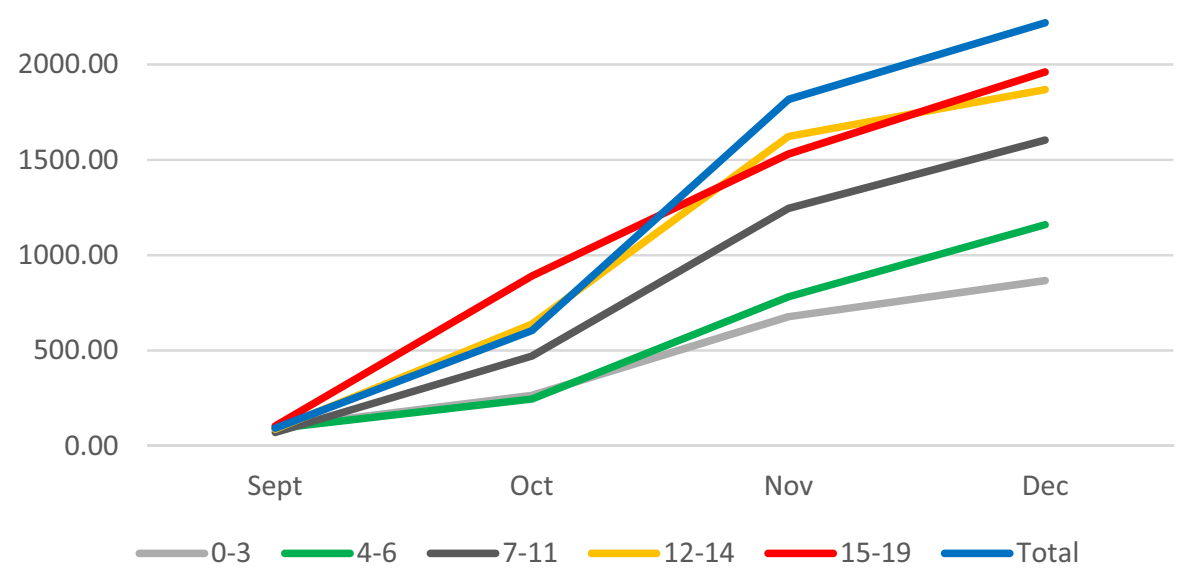


Table 5 Colours related to COVID-19 risks, assigned weekly to the regions of Italy, 6 November, 23 December 2020

\begin{tabular}{llllll}
\hline & Lombardia & FVG & Veneto & Campania & Lazio \\
\hline $6 / 11-14 / 11$ & Red & Yellow & Yellow & Yellow & Yellow \\
$15 / 11-28 / 11$ & Red & Orange & Yellow & Red & Yellow \\
$29 / 11-05 / 12$ & Orange & Orange & Yellow & Red & Yellow \\
$06 / 12-12 / 12$ & Orange & Yellow & Yellow & Orange & Yellow \\
$13 / 12-23 / 12$ & Yellow & Yellow & Yellow & Orange & Yellow \\
\hline
\end{tabular}

increased, being greater than the average level, for young people over the age of 11 for the whole period. In October, this dynamics was also observed for children between the ages of six and 11. Comparing the incidence in the entire population with that in the young age classes in Italy and in its regions, it seems to be evident that the introduction of online lessons contributed to reducing the spread of the virus among the young age classes.

Examining the same phenomenon in the five regions that we considered for a more detailed analysis (Lombardia, Friuli Venezia Giulia, Campania, and Lazio) revealed that it is extremely important to also consider other factors that might influence the pandemic, specifically the level of restrictions applied in each area. In the two regions that were declared red zones during the second wave (Lombardia and Campania), the incidence among young people began to diminish from November. In the other two regions, Friuli Venezia Giulia (orange zone) and Veneto (yellow zone), the incidence among young people continued to increase but at a slower pace. In Lazio (yellow zone), in contrast, the incidence among children and adolescents kept increasing faster than that in the total population. However, this is the region, out of the five that
Fig. 7 Monthly incidence of COVID-19 per 100,000 inhabitants, total population and young age classes, September-December 2020, Campania and Lazio

\section{Campania}

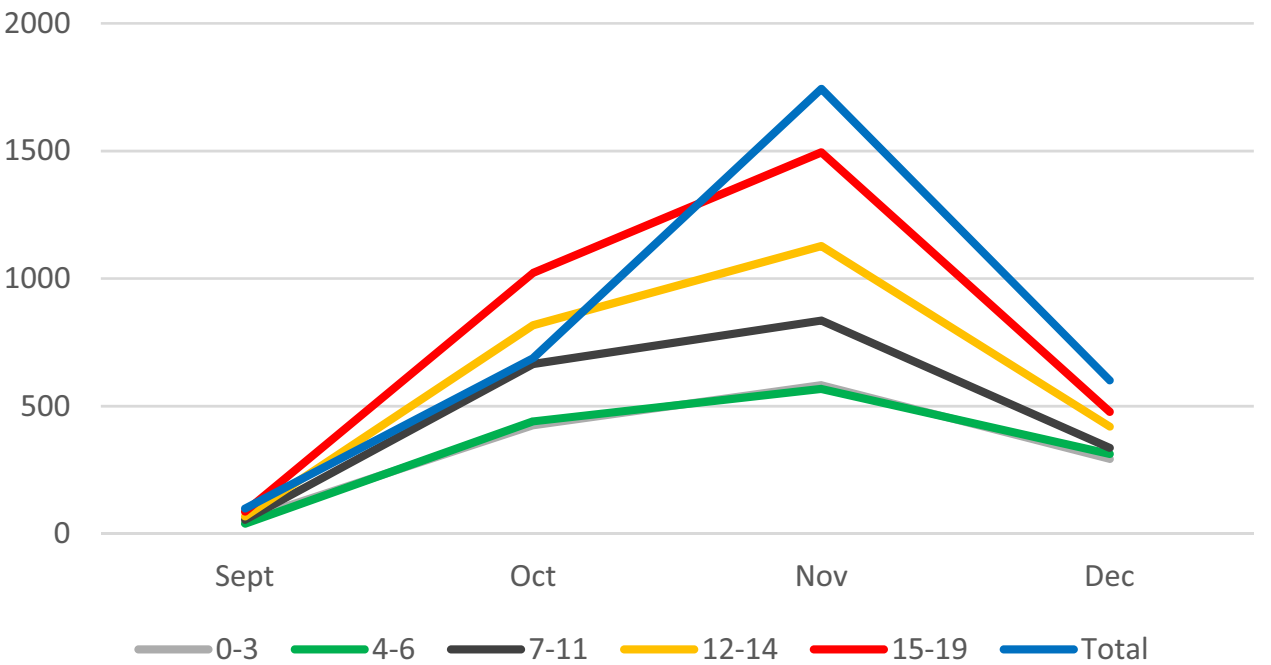

\section{Lazio}

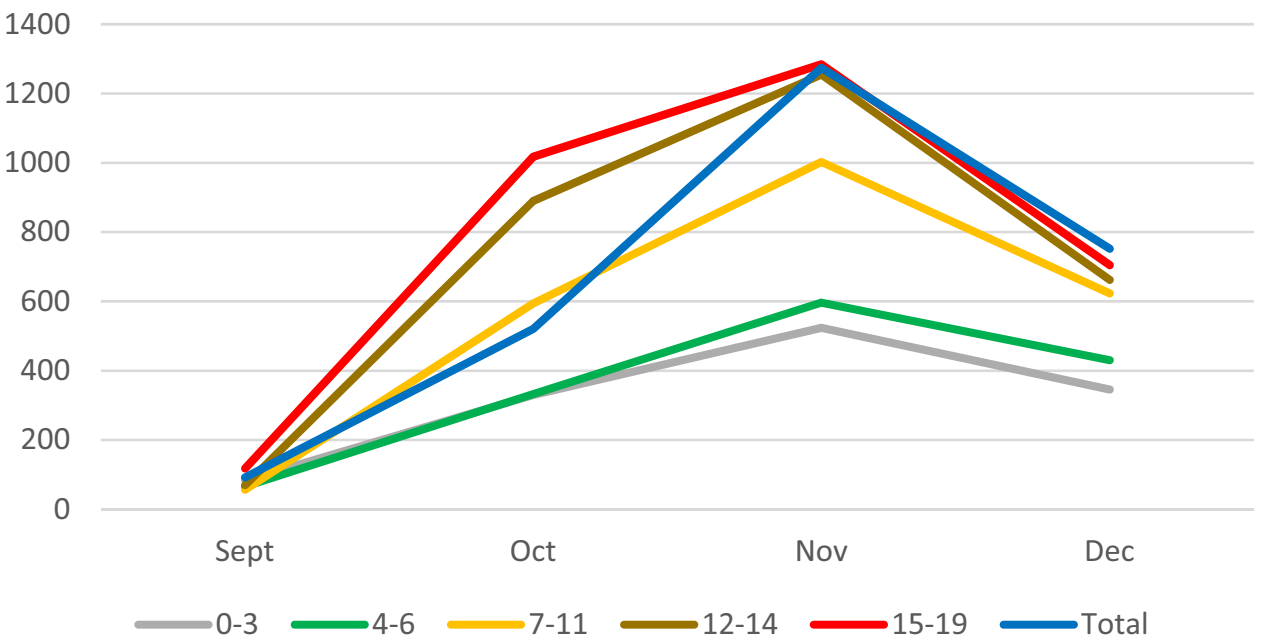




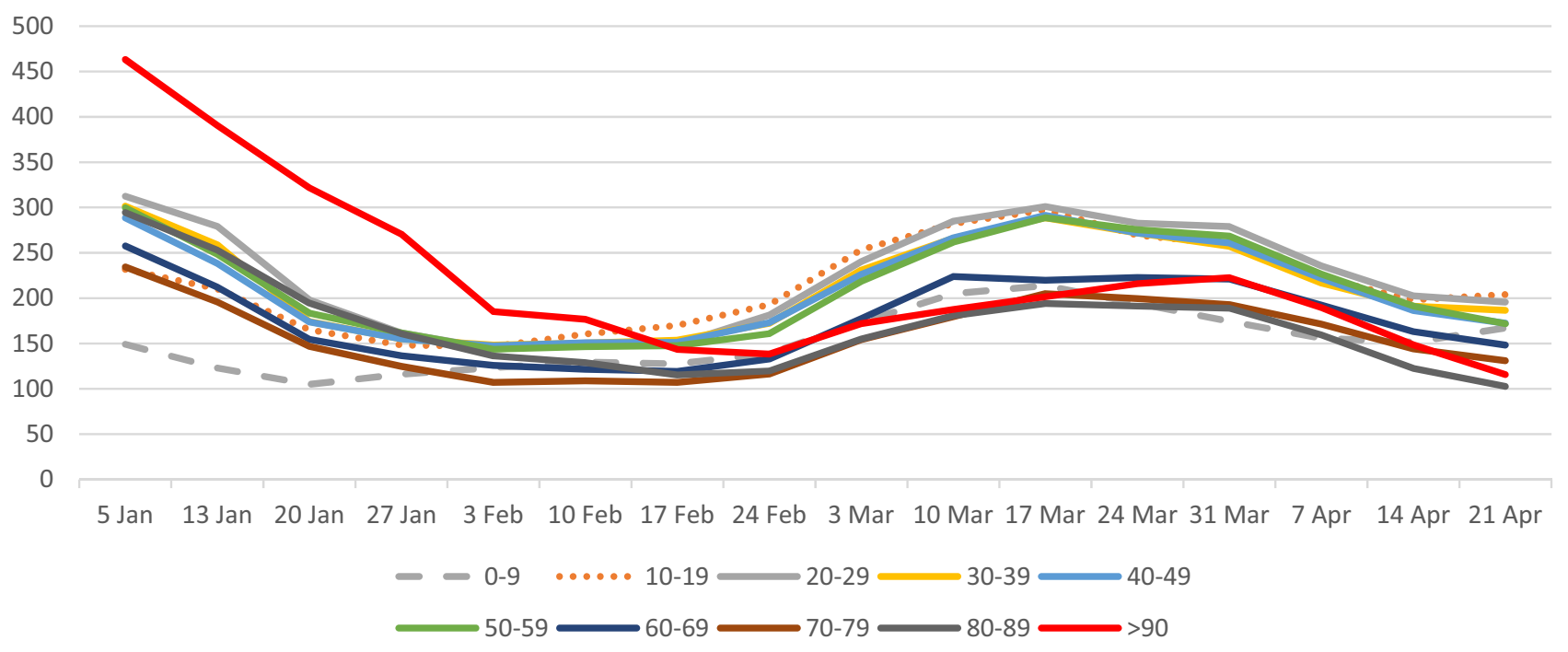

Fig. 8 Weekly incidence of COVID-19 per 100,000 inhabitants, 10-year age classes, January-April 2021, Italy

we considered, that had the lowest absolute levels of monthly incidence of COVID-19 per 100,000 inhabitants.

\section{Evolution of the COVID-19 infection among young people: third wave in Italy}

Figure 8 depicts the dynamics of the COVID-19 weekly incidence per 100,000 inhabitants from January to April 2021. The incidence was calculated based on the data of infections by 10-year classes of age that was published weekly by ISS for the entire country. Unfortunately, more disaggregated data are not publicly available. Even with this gross detail regarding the age of the patients, some interesting evidence can be observed regarding the diffusion of the virus among young people. Since the beginning of February 2021, the highest weekly incidence was registered for the ages between 10 and 19 years. Only at the end of March, the weekly incidence started to decrease; however, it remained higher than the average level. With regard to the weekly incidence in the youngest ages ( $0-9$ years), while it had been the lowest until February, it started to increase after that, exceeding that for much older people, such as those aged between 60 and 89 years. From the end of March, incidence decreased again.

The decree of the Italian Prime Minister of 2 March 2021 imposed the closure of all types of schools in the regions classified as red zones. In March 2021, the restrictions of the red zone were imposed in 11 Italian regions and one autonomous province, with all schools being closed.

Figure 9 illustrates the distribution of infections by age classes during the months of the second and third waves
Fig. 9 Distribution of monthly cases of COVID-19 by age classes, October 2020-April 2021, Italy

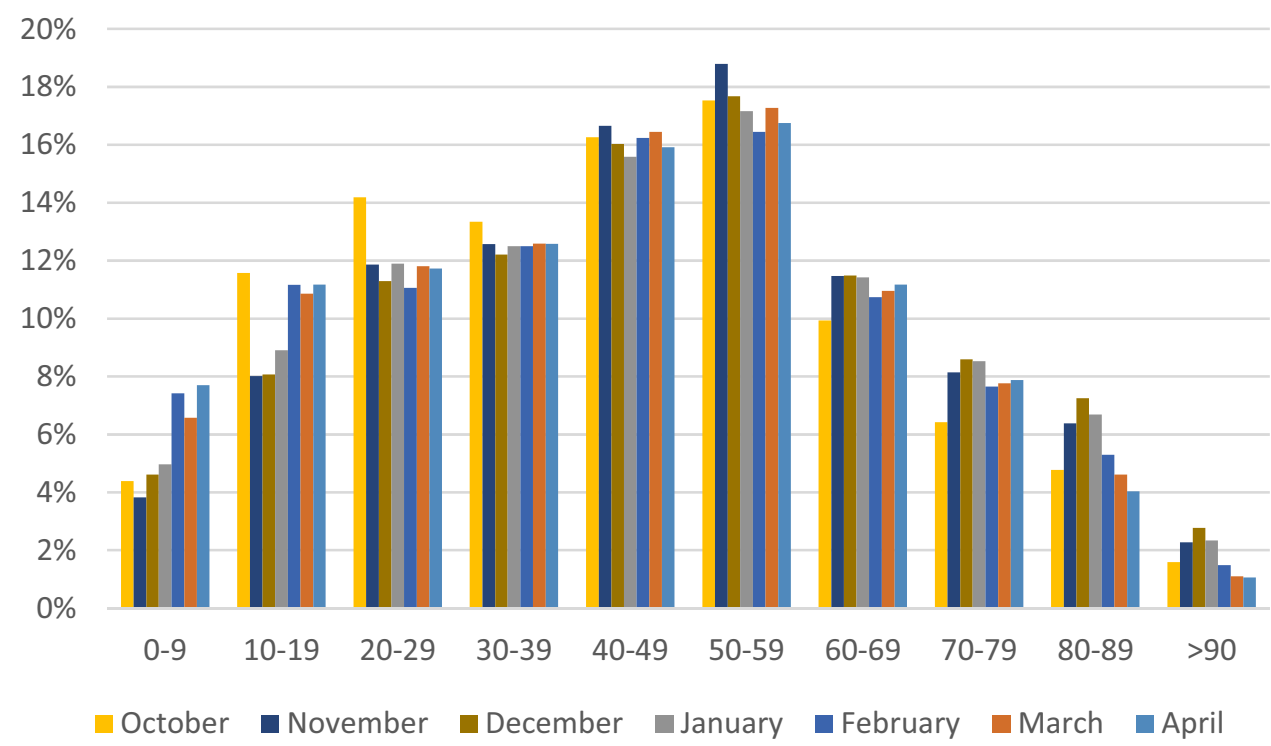


of the pandemic in Italy. In addition, from this figure, it is possible to see that cases among the youngest patients diminished after schools were closed.

The increase of new cases of COVID-19 among young patients during the third wave has been attributed by many researchers to the diffusion of new variants of the virus [20].

\section{Concluding remarks}

The analysis of the dynamics of COVID-19 infections among young people in Italy shows that there exists a correlation between incidence and school closures both during the second and the third waves of the pandemic. Specifically, school closures mitigated the growth of infection, especially among patients aged between 14 and 19 years, who attended high school during the second wave. Children were involved during the third wave as well.

Certainly, this mitigation effect was facilitated by the restrictions imposed by the Italian government to reduce physical contact among people. In any case, the incidence among children and adolescents reduced —or slowed down compared to that in the total population-concurrently with school closures.

Observational data, as those publicly available, do not allow the establishment of causal links between phenomena. However, they can reveal significant associations among them. To evaluate the effects of the restrictions implemented to reduce the diffusion of the virus, experimental studies need to be conducted. We hope that such studies can be conducted in Italy. This would require the availability of more disaggregated data to the researchers.

Another important information that is presumably collected by epidemiological services but is not available for research includes the modes of virus transmissions, such as information about how children and adolescents get infected, how they transmit infections, and who their principal and most at-risk contacts are (parents, friends, or schoolmates).

In the period following our analyses, the ISS started to publish weekly data on incidence for school-age groups that allow a study of the evolution of the infection in paediatric classes and with comparison to the other age groups and the whole Italian population. These data are not disaggregated by region, but refer to the entire country; however, they deserve a future study also in view of the fact that the youngest students (until 12 years old) cannot at the present moment be vaccinated, while the vaccination campaign for all other people started in January 2021. A larger diffusion of the virus could be expected among youngest patients in the subsequent waves of the pandemic.

\section{Appendix}

See Tables 6, 7, 8, and 9.

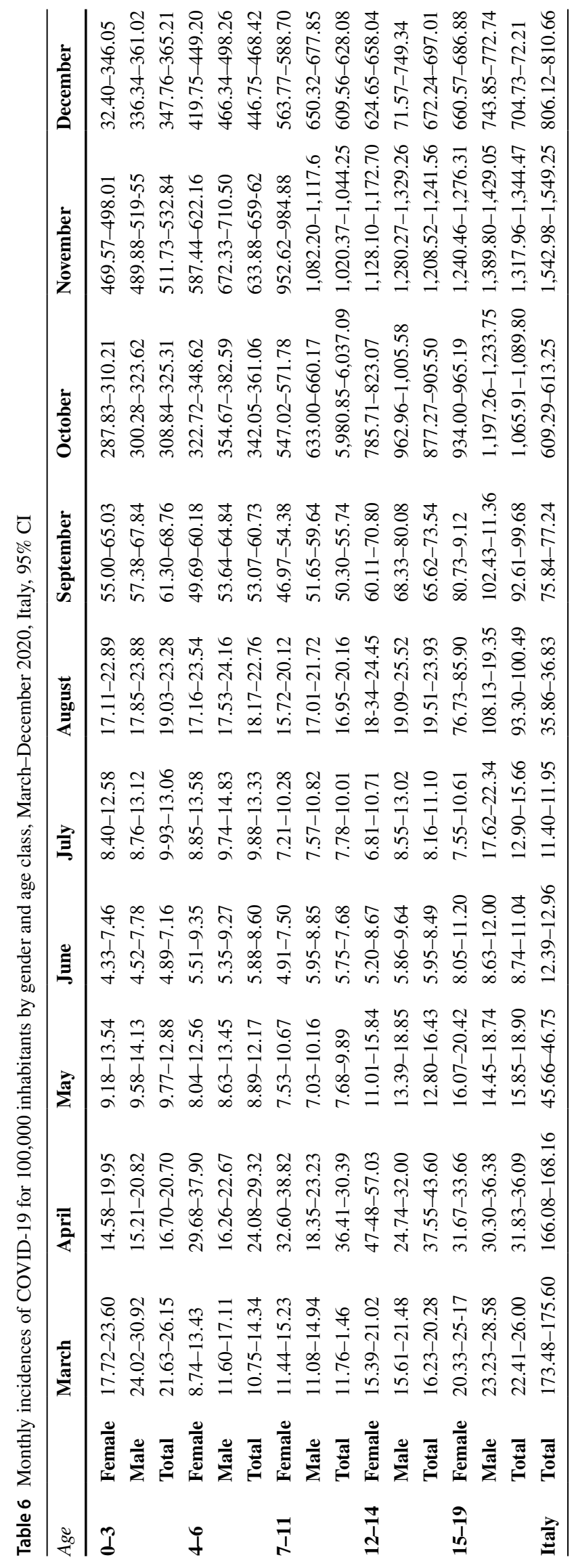



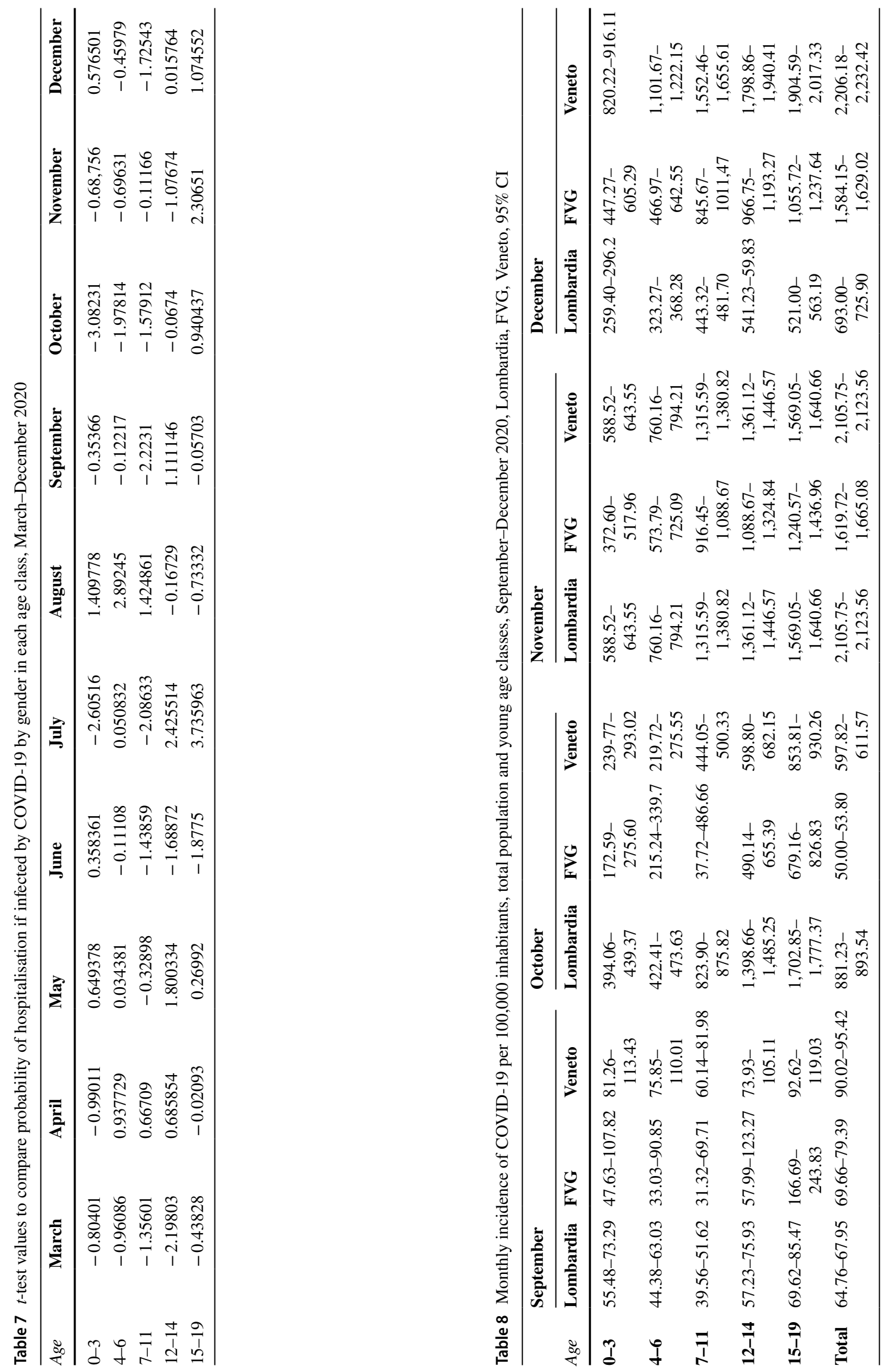
Table 9 Monthly incidence of COVID-19 per 100,000 inhabitants, total population and young age classes, September-December 2020, Campania, Lazio, 95\% CI

\begin{tabular}{|c|c|c|c|c|c|c|c|c|}
\hline \multirow[b]{2}{*}{ Age } & \multicolumn{2}{|l|}{ September } & \multicolumn{2}{|l|}{ October } & \multicolumn{2}{|l|}{ November } & \multicolumn{2}{|l|}{ December } \\
\hline & Campania & Lazio & Campania & Lazio & Campania & Lazio & Campania & Lazio \\
\hline 0-3 & $45.18-66.92$ & 70.29-97.76 & $398-59-457.09$ & $303-61-375.95$ & $549.82-617.9$ & $490.30-557.67$ & $270.05-318.49$ & $318.73-374.34$ \\
\hline $4-6$ & $31.65-51.92$ & $53.20-79.36$ & $408.76-475.17$ & $304.24-363.01$ & $531-61-606.94$ & $558.31-636.88$ & 285.99-341.99 & $397.70-464.48$ \\
\hline $7-11$ & $46.72-63.94$ & 48.15-66.09 & $636.56-696.25$ & $565.39-623.24$ & $802.59-869.39$ & $965.34-1,040.33$ & $337.07-359.02$ & 594.19-653.44 \\
\hline $12-14$ & $57.16-81.15$ & $57.97-83.68$ & $777.61-860.05$ & $845.23-936.25$ & $\begin{array}{r}1,079.98- \\
1,176.60\end{array}$ & $\begin{array}{r}1,202.15- \\
1,310.04\end{array}$ & $391.49-450.72$ & $624.14-702.78$ \\
\hline 15-19 & 77.85-98.38 & $105.34-131.49$ & $101.34-108.53$ & $\begin{array}{l}979.84- \\
1,056.26\end{array}$ & $\begin{array}{r}1,453.47- \\
1537,58\end{array}$ & $\begin{array}{l}2,800.98-2,927- \\
\quad 97\end{array}$ & $454.89-502.72$ & $673.49-737.20$ \\
\hline Total & $96.82-101.98$ & $89.36-94.31$ & $681.77-695.33$ & $514.46-526.21$ & $\begin{array}{r}1,732.59- \\
1,754.05\end{array}$ & $\begin{array}{r}1,265.40- \\
1,283.72\end{array}$ & $595.11-607.79$ & $744.77-758.88$ \\
\hline
\end{tabular}

Authors' Contributions Both authors conceptualised the study and chose the appropriate methodology. Francesca Bassi made the statistical analyses. Both authors wrote the manuscript.

\section{Declarations}

Ethics approval N/A.

Consent to participate N/A.

Consent for publication N/A.

Conflict of interest The authors declare no competing interests.

\section{References}

1. Leeb RT, Price S, Sliwa S, Kimball A, Szucs L, Caruso E et al (2020) COVID-19 trends among school-aged children - United States, March 1-September 19, 2020. Morb Mortal Wkly Rep 69(39):1410-1415

2. Götzinger F, Santiago-García B, Noguera-Julián A, Lanaspa M, Lancella L, Calò Carducci FI et al (2020) COVID-19 in children and adolescents in Europe: a multinational, multicentre cohort study. Lancet 4:653-661

3. Gupta S, Malhotra N, Gupta N, Agrawal S, Ish PT, curious case of coronavirus disease of, (2019) Letter to the editor. J Pediatr 222:258-259

4. Dattner I, Goldberg Y, Katriel G, Yaari R, Gal N, Miron Y et al (2021) The role of children in the spread of COVID-19: using household data from Bnei Brak, Israel to estimate the relative susceptibility and infectivity of children. PLOS Comput Biol. https://doi.org/ 10.1371/journal.pcbi.1008559

5. Amodio E, Battisti M, Kourtellos A, Maggio G, Maida CM. School opening and COVID-19 diffusion: evidence from geolocalized microdata. COVID Economics 65:47-77

6. Stein-Zamir C, Abramson S, Shoob H, Libal E, Bitan M, Cardash $\mathrm{T}$ et al (2020) A large COVID-19 outbreak in a high school 10 days after schools' reopening, Israel, May 2020. Europe's Journal on Infectious Disease Surveillance, Epidemiology, Prevention and Control 25(29):pii=2001352. https://doi.org/10.2807/1560-7917. ES.2020.25.29.2001352

7. Aiano F, Mensah A, McOwat K, Obi C, Vusirikala A, Powell AA et al (2021) COVID-19 outbreaks following full reopening of primary and secondary schools in England: retrospective, cross-sectional national surveillance. Available at SSRN: https://ssrn.com/abstract=3766014 or https://doi.org/10.2139/ssrn.3766014

8. Ludvigsson JF (2020) Children are unlikely to be the main drivers of the COVID-19 pandemic - a systematic review. Acta Pediatrica 2020(109):1525-1530

9. Gras-Le Guen C, Hentgen V, Dubos F, Ferrara P, Pettoello-Mantovani M, Cohen et al (2021) Pediatric societies call for school to stay open amid the coronavirus disease 2019 pandemic. J Pediatr. https://doi. org/10.1016/j.jpeds.2021.04.001

10. Nagakumar P, Chakwick C, Bush A (2021) Gupta, A Collateral impact of COVID-19: why should children continue to suffer? Eur J pediatr 180:1975-2197

11. UNESCO (2021) One year into COVID: prioritizing education recovery to avoid a generational catastrophe

12. Istituto Superiore di Sanità (2021a) Rapporto ISS COVID-19 n.63 2020. Apertura delle scuole e andamento dei casi confermati di Sars-CoV-2: la situazione in Italia

13. Istituto Superiore di Sanità. Epidemia COVID-19. Aggiornamento nazionale https://www.epicentro.iss.it/coronavirus/sars-cov-2sorveglianza-dati. Accessed 2nd May 2021.

14. Arbia G, Bassi F (2021) Falorsi, PD Observed and estimated prevalence of COVID-19 in Italy: how to estimate the total cases from medical swabs data. Sci Total Environ 764:1-5. https://doi. org/10.1016/j.scitotenv.2020.142799

15. Dong Y, Mo X, Hu Y, Qi X, Jiang F, Jiang Z et al. Epidemiology of COVID-19 among children in China. Pediatrics 145(6):1-10

16. Lubrano L, Bloise S, Testa A, Marcellino A, Dilillo A, Mallardo $S$ et al (2021) Assessment of respiratory function in infants and young children wearing face masks during the COVID-19 pandemic. JAMA Netw Open 4(3):e210414. https://doi.org/10.1001/ jamanetworkopen.2021.0414

17. Long SS (2020) A picture of severe COVID-19 in US children and youth emerges. J Pediatr Perspective to the Editor 223:1-5

18. Decreto del Presidente del Consiglio dei Ministri 3 Novembre 2020. https://www.gazzettaufficiale.it/eli/id/2020/11/04/20A06109/sg

19. Istituto Superiore di Sanità (2020b). Monitoraggio Fase 2 Report settimanale. https://www.iss.it/monitoraggio-settimanale. Accessed 2nd May 2021

20. Korber B, Fischer WM, Gnanakaran S, Yoon H, Theiler J, Abfalterer W, Hengartner $\mathrm{N}$ et al (2020) Tracking changes in SARS-CoV-2 spike: evidence that D614G increases infectivity of the COVID-19 virus. Cell 182(4):812-827

Publisher's Note Springer Nature remains neutral with regard to jurisdictional claims in published maps and institutional affiliations. 